\title{
Judi Rhodes' Farewell Address
}

Dear TOS Members,

In July I will be leaving TOS after over 10 years as your Executive Director and I will leave with mixed emotions. On one hand, I am anxious to start the next chapter of my life, but, on the other, I will sincerely miss being associated with this terrific organization.

The TOS Council has graciously thanked me for my years of service, but I must thank all of you for the opportunity to have been involved with the Society and all that it strives to do and be. Thanks, too, for allowing me to learn so much from you, which I've considered the most valuable fringe benefit of the job. My background before TOS was decidedly unscientific. With the help of Oceanograply, all the TOS meetings and my association with the members, my position provided me with a fantastic layperson's education in a field in which I otherwise would have had only the most rudimentary bits of information. I consider myself extremely fortunate to have met and worked with so many knowledgeable, dedicated professionals who are also genuinely nice people.

When I first interviewed for the position with Jim Baker and Stan Wilson at the end of 1989, I had recently arrived in Washington, DC from Los Angeles. At one point, Stan asked me how I thought I would get along with a bunch of science geeks after all those Hollywood types I was probably used to. Ten years later, I can honestly say, I would take oceanographers over Hollywood types (with the possible exception of Harrison Ford or Pierce Brosnan) any day of the week!

With all my best wishes to TOS, its members, and your new Executive Director, Jenny Ramarui,

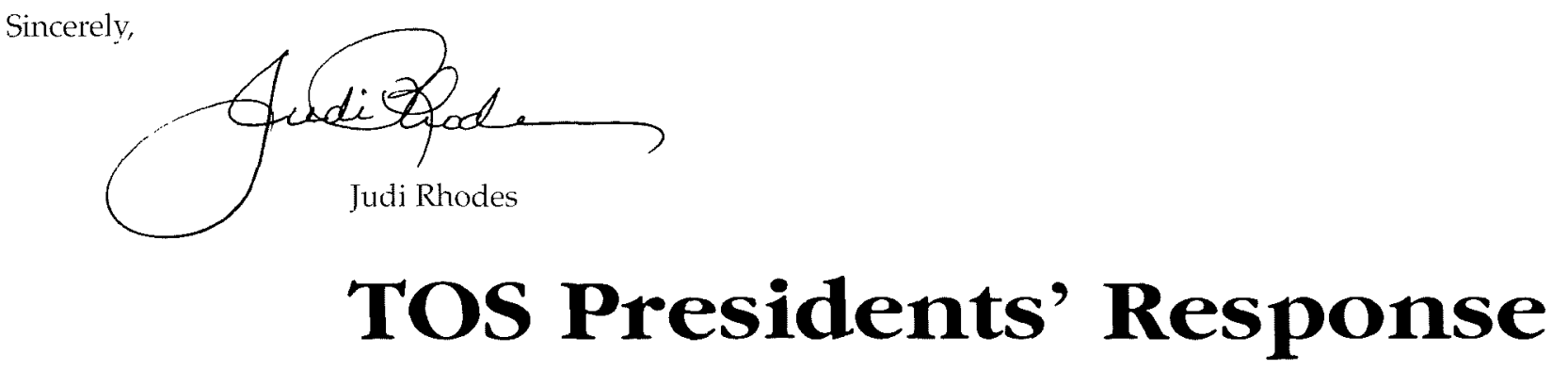

Dear Judi,

We wish you well with your new enterprises, but we are sad to see you go. You and The Oceanography Society have become so intertwined that it is difficult to see where one stops and the other begins. Your closeness with the Society has sometimes led you to sacrifice yourself for the good of the cause in quiet and too often under-appreciated ways. So, for all of us TOS presidents, this parting is a poignant moment.

You thank the Society for teaching you about the oceans. We need to thank you for teaching us about operating this organization. You always seemed to know how to get things done, and what sorts of approaches would or would not work. You have watched the affairs of the Society on a day-to-day basis and conveyed your insights to us whether they were welcome or (what is more important) not.

We can now only say "thank you" and wish you well as you move forward. Somehow, you will never seem far away.

With our best wishes,

D. James Baker Arnold Gordon Margaret Leinen
1988-1992

1992-1994

1994-1996
Robert Duce Kenneth Brink James Yoder
1996-1998

1998-2000

2000-2002 